\title{
Language Politics, Monolingual Ethos and Linguistic Pluralism in Ethiopia: Lesson from Wollo Oromo
}

\author{
Shimellis Hailu ${ }^{1, *}$, Negash Abebe ${ }^{2}$ \\ ${ }^{1}$ Department of Political Science and International Relations, College of Social Science and Humanities, Wollo University, Dessie, Ethiopia \\ ${ }^{2}$ Department of Social Anthropology, College of Social Science and Humanities, Wollo University, Dessie, Ethiopia
}

Email address:

kumarraatura@gmail.com (S. Hailu), negashtufa@gmail.com (N. Abebe)

${ }^{*}$ Corresponding author

\section{To cite this article:}

Shimellis Hailu, Negash Abebe. Language Politics, Monolingual Ethos and Linguistic Pluralism in Ethiopia: Lesson from Wollo Oromo. International and Public Affairs. Vol. 4, No. 1, 2020, pp. 8-19. doi: 10.11648/j.ipa.20200401.12

Received: September 1, 2019; Accepted: October 30, 2019; Published: August 4, 2020

\begin{abstract}
This study examines the effects of post 1991 Ethiopian language policy on Wollo Oromo. Specifically, the study discusses language politics, monolingual ethos and linguistic pluralism in Ethiopia by focusing on Wollo Oromo. To realize the objectives of the study, the researchers employed both qualitative and quantitative research approach (mixed), which enabled the researchers to explore the socio-economic significance of multilingual policy and challenges in the study community. In this study, both primary and secondary data collection techniques were used. The primary sources of data were collected via interviews, Focus Group Discussion and Questionnaires. Finally, both the secondary and primary data were organized thematically and analyzed just to increase the consistency and strength of the finding of the study. Besides, the quantitative data is analyzed using SPSS version 20. Based on this, the researchers reach upon the following finding; the finding prevail that multilingual policy is significant for local socio-economic development, exploration of local knowledge and innovation. The finding also prevail that learning in mother tongue enhances children learning capacity. The overall data shows that the Oromo nationality zone people are happy with the current multilingual language policy. Nevertheless, the policy implementation is not free from challenges. Among others the implementation of multilingual language policy is challenged by monolingual ethos, politicization of language, lack of understanding and misconception of parents about the use of learning in mother language, attitudes toward local languages and lack of enough materials and teachers for the teaching of this language. Hence, there is the need to depoliticize language and have comprehensive language academy, which develop comprehensive curriculum and create awareness about significances of multilingualism.
\end{abstract}

Keywords: Language Politics, Language Policy, Language Pluralism, Monolingual Ethos

\section{Introduction}

In the historical continuum that informs, as described by TeshaleTibebu, cited in Keller, the making and remaking of modern Ethiopia, the second half of the $19^{\text {th }}$ century was shaped by the wars of incorporation and state formation on unequal terms. In many major ways, class and national struggles intended to end the asymmetrical relations, have shaped the second half of the $20^{\text {th }}$ century [1]. In other words while the wars of the $19^{\text {th }}$ century were for the making of modern Ethiopia, the struggles of the $20^{\text {th }}$ century were for the reversal of the same historical process that created the multi-ethnic polity of Ethiopia [2]. To be more specific, the class struggle and national/ethnic struggles of the 1960s and 1970 s that precipitated the revolution of 1974 , the various struggles that led to the change of regime in 1991 and the ongoing struggles for self-rule and democracy are part of the remaking of Ethiopia [3].

Since the making of Ethiopia in $19^{\text {th }}$ Century, Ethiopia becomes a multilingual, multiethnic and cultural pluralist country. Above all, it is never colonized while almost all African countries were colonized. Nevertheless, Ethiopia's language use policy had not been the reflection of this diversity and historical autonomy. In those days of the introduction of modern education into Ethiopia, the medium of instruction used to be foreign language. The first modern formal school in Ethiopia, Menelik II School, was primarily 
limited to teaching European languages such as French, Italian and English with the exception of the Italian occupation period during which attempt was made to make some local languages medium of instruction [4].

Despite the linguistic and ethnic multiplicity of the country, English has continued to spread getting more dominance and importance not only in education but also in business and administration. In every aspect of cities and towns English and Amharic languages are neck in neck. But, the politicizing of ethnicity and legalization of multilingual system arise a debate among politicians, scholars and elites concerning the legalization of ethnic federalism in general and multilingualism in particular. Some groups argued that introduction of ethnic federalism in general and multilingualism in particular is divisible policy, which divided Ethiopia into different nation states like Yugoslavia and USSR. Besides, some centralists are also advocator of monolingualism based on the argument of economic growth, which would improve efficiency (Adeno 2001) as cited in [5]

On the other hand, other scholars perceive the politicizing of ethnicity in general and multilingualism in particular as the panacea to historic Ethiopian national operation. For example, Milkessa write that the major achievement of the contemporary FDRE constitution, as compare to previous constitution, is the inclusion of the provision that bestows opportunity for members of the federation to determine their respective official languages. In his two studies dedicated to Ethiopian language policy, he appreciated multilingual policy recommending further diversification at federal level [6]. Similarly, Adeno suggested that it is not linguistic diversity that leads to conflict rather than it is the dominance over certain linguistic groups that lead to disunity [5].

However, the heated debate among scholars discussed above rarely substantiated by empirical facts on the ground from the target population. Therefore, the purpose of this paper is to investigate the practice of multilingual policy in Ethiopia taking Wollo Oromo as case studies in order to contribute in negotiating the heated debate on post 1991 Ethiopian multilingual policy and monolingual ethos. Hence, this paper has the general objective of exploring the effects of post 1991 language policy in Ethiopia on Wollo Oromo.

\section{Materials and Methods}

For this study, a mixed research approach; both qualitative and quantitative research approach was employed to gather both primary and secondary data sources. There are strong reasons for the use of integrated research design for this study: the strengths and weaknesses of qualitative and quantitative methods often complement each other. Therefore, the mixed method design was used in this study. The mixed approach contains different strategic model; from these the researchers select sequential exploratory strategy. This is because sequential exploratory strategy helps researchers to confirm, cross-validate or corporate a finding of data collected using two different methods in a single study. This model uses separate quantitative and qualitative methods as a means of offset the weaknesses inherent within one method with the strengths of other methods. Therefore, it is the straightforward strategy to explore the effects of language policy on Wollo Oromo since the institutionalization of language pluralism by using cross-validating qualitative and quantitative data. The qualitative data gathered through indepth interviews and Focus Group Discussions are crossvalidated against quantitative data collected using Questionnaires.

\subsection{Population, Sample and Sampling Techniques}

The population for this study is all populations of wollo Oromo (the current Oromo nationality zone) reside in Amhara national regional state. Whereas the target population is the all population using Afaan Oromo language in different services like education, court services, administrative and other social services. There are seven Woredas in the Oromo nationality zone; five rural Woredas and two-town administration. For the purposes of getting complete information assessment was done in all woredas, hence all woredas are totally taken. But, to identify individual sample from all woredas both Convenient and purposive sampling techniques was used. Purposive sampling is used to select individuals sample for interviews and focus group discussion considering the experiences of individuals in study areas, other scholars undertaking study on language policy in Ethiopia and concerned government officials.

From each woredas individuals for questionnaires were selected using convenience sampling techniques which is a method by which a researchers like purposive sampling intentionally draws samples considering certain factors that are deemed to be relevant for the research [7]. The researchers considered availability of target population and conducive environment for data collection as selection criteria. Therefore, the researchers' employed convenience sampling technique to include any individuals getting public services using Afaan Oromo language in the study area and available at the time of data collection.

\subsection{Sources, Methods of Data Collections and Analysis}

In order to accomplish the purposes of this research, both secondary and primary sources of data were collected. As far as secondary sources are concerned, books, journal articles, newspapers, government enactments, legal instruments, organizational reports and official documents were reviewed. To this end, reviewing relevant literature to compile in a form of over view of what is currently known about the use of multilingual policy in worldwide in general and Ethiopia in particular were carried out. Also, document analysis were made to draw together existing data on the significance and challenges of multilingual policy in Wollo Oromo. Using secondary sources as base, primary sources were collected from target population using interviews, questionnaires and Focus Group Discussion (FGD).

Finally, quantitative data is analyzed using descriptive 
analysis. Both Statistical Package for Social Science (SPSS) and Simple statistical techniques like means, percentages and tables was used for this purpose. While qualitative data is analyzed by arranging and portraying the data collected through interviews and FGD in a way that help to detect patterns or problems, explore associations that exist in the data. In this analysis, reiteration and elaborations of key concepts and suggestions was made on the findings that fit with the existing literature under investigation. In doing so the researchers identified dissimilarities while comparing the findings secured against literature reviews.

\section{Literature Reviews}

This section discusses about literatures in language issues. To be specific, issues about language policies, language politics, monolingual ethos, multilingualism, debate on mother tongue education and significances of multilingual/language pluralism in multiethnic society like Ethiopia.

\subsection{Language Policy}

According to Getachew and Deribe a language policy is a high level governmental document that sets decisions and guidelines for and determines what language and for which purposes shall be used in a given country. In other words, language policies are legal but political decisions on the statuses, developments, and functions of languages in a state. In addition, language policy is about deciding on the networking of languages. It involves choice of functions and the choice of language to perform each of them. The choice is made for a purpose to serve the perceived need of the maker of the choice. The common assumption is that it is the government, or a central body authorized by it, makes the policy. This policy is naturally for the country and its purpose is to meet the needs of the country [8].

The notion of language policy is related to decisions, rules, regulations and guidelines concerning the status, use, domains and territories of language, the rights of the speakers under consideration, the determination of whether a particular language (s) should have the status of recognition as a national language, language of wider communication, working language, language of instruction etc. As such, language policy involves the development of public policies aimed at using the state's authority to influence various aspects of the status and use of language by people in a state [9].

It is instigated by the time it is felt that the intervention of the state is required to determine the status and use of language in the society. In this regard, therefore, language policies and the classifications thereof differ from place to place and from time to time according to the political orientations of governments and the nature of the society in question. Accordingly, some governments have clear and explicit language policies called overt policies, which have written support in legal documents like the constitution. Others avoid this explicit approach and do not state their language policies in written legal documents, opting for covert language policies. The 1995 FDRE Constitution states that all Ethiopian languages shall enjoy equal state recognition (Art. 5 (1)), Amharic shall be the working language of the federal government (Art. 5 (2)) and regions have the right to determine their respective regional government working languages (Art. 5 (3)). However, there is no detail language policy in Ethiopia.

\subsubsection{Monolingual Language Policy}

General dictionary and specialist Linguistic dictionaries define monolingual as follow;

1. Able to speak only one language

2. Said of one person/community with only one language, also unilingual

3. A person who knows and uses only one language, though perhaps a passive knowledge of others (Longman dictionary of Language Teaching and Applied Linguistic)

4. Speaks, writes and understands only one language (short oxford dictionary)

This definition of monolingual is overlapping with the extreme definition of bilingual, which consider that no adult human being is monolingual since an adult can at least now one word from other languages, which according to this group qualified a person as bilingual.

According to the monolingual policy, only one language and culture, usually that of the majority would be adopted as the national language and culture to the exclusion of the minority languages [10]. In fact, this is the policy used in Europe, where dominant languages like English, French and Spanish were adopted in their respective countries at the expense of minority languages like Alsatian, Basque, Breton, Catalan, Cornish, Irish Gaelic, Lorrainian, Scottish Gaelic, Welsh and others. The advantage of this approach is that it promotes one national medium of communication for the whole country and allows for one cultural identity and a sense of common belonging. In contrary, such a policy tends to marginalize the speakers of the other languages who are then forced to operate in a language in which they have no or limited competence.

\subsubsection{Bilingual Language Policy}

Bilingual is defined differently by different scholars and dictionaries. The major dictionaries definition of bilingual is;

1. Having the ability to speak two languages:

2. Spoken or written in two different languages (bilingual dictionary)

3. Characterized by the use or presence of two languages (bilingual education)

There is no universal definition of bilingualism, however, each definition that has been given to this term shared the same interpretation. A person is bilingual if they are able to speak or use two languages, although the given definitions may vary in terms of language ability and language usage of an individual [11]. If we define bilingualism according to the syllables of the word, this will simply mean: bi- means having two and lingua -derived from Latin, tongue or 
language. Therefore, bilingualism will literally mean "having two tongues or languages".

Moreover, Ellis state that bilingualism is the psychological state of an individual who has access to more than one linguistic code as a means of social communication: the degree of access will vary along a number of dimensions which are psychological, cognitive, psycholinguistic, social psychological, sociological, sociolinguistic, socio-cultural and linguistic [12].

Bilingualism entails cognitive advantages, as bilingual children have two or more words for each concept and they demonstrate greater mental flexibility and creative thinking than monolinguals [13]. The knowledge of two languages provides a head start for the learning of other languages [14] as it enables children to think about languages [15]. Since subject matter is taught by means of language, a high level of proficiency in the languages of schooling is a valuable asset. Learning more than one language also involves increased chances of communication with a wider variety of people, at a local and global level [11] and an appreciation of different cultures, which could lead to multicultural tolerance.

\subsubsection{Multilingual Language Policy}

According to Batibo, the multilingual policy advocates the promotion and use of each language and culture in the country. This approach allows the codification and elaboration of each of the languages for use within its own socio-political and cultural confines. The extent to which each language will be used in the public domains would depend on its size, vitality and level of development. This approach, despite its many costs and logistic problems, has the advantage of encouraging the development and use of each of the languages in a country. Moreover, it gives equal chances to all citizens to participate in national affairs, therefore contributing to true democracy [2005].

Multilingual language policy can be societal and individual phenomenon. In Ethiopia, these days, the main aim of the language policy is enabling nations and nationalities to use their respective languages for various purposes. It encourages all nations and nationalities to use their mother tongues as media of multiple purposes - it does not encourage them to learn two or more indigenous languages by using the languages as media of instruction, or by offering them as school subjects. Therefore, as the study bases on such circumstances, its focus is on the societal multilingual language policy of the country.

At the back of multilingual language policy, there are always tide of political change, political initiative, and expressions of political discourses. What might be presented as pure motives - minority languages' preservation and use as media of instruction in a given country - may hide basic political discourses and political assumptions. Surrounding multilingual language policy are always political debates about national unity, identity and control by elites in power, questions about social order, and the perceived potential subversiveness of language minorities [4].

\subsection{Monolingual Ethos}

At the level of society, a monolingual community is one which, has at its disposal input from only one language and that the members of these communities are destined to be native monolinguals. Monolingualism prevails in most of the Western world and parts of the non-Western world (such as parts of Asia and Africa) whether it be via officially imposed unilingualism - monolingualism dictated or supported by legislation - or simply functionally imposed by hegemonic forces, which can be both overt and covert. So, while there are a number of minority languages in France, the United States, China and Angola for example, French, English, Mandarin and Portuguese respectively are clearly hegemonic languages in these domains, which for the majority of the population, constitute the only input readily available. Such a scenario is very different from the situation of Quebec, Haiti and Switzerland where at least two languages are, to a greater or lesser extent and of course delimited by social context, available to most speakers.

\subsection{Language Politics}

The scholar states that language is 'the universal capacity of humans in all societies to communicate, while politic means 'the art of governance'. Thus, the language as an instrument to interact or transact in various situations and/or in different organizations being conventionally recognized as political environment. It is generally accepted that the strategy that one group of people takes to make the other group of people do what it intends to be done is known as a linguistic strategy. It involves manipulative application of the language. Therefore, 'linguistic manipulation is the conscious use of language in a devious way to control the others'. Pragmatically speaking, linguistic manipulation is based on the use of indirect speech acts, which are focused on prelocutionary effects of what is said. There are a number of institutional domains and social situations in which linguistic manipulation can be systematically observed, for example in cross-examination of witnesses in a court of law.

Linguistic manipulation can be considered also as an influential instrument of political rhetoric because political discourse is primarily focused on persuading people to take specified political actions or to make crucial political decisions. To convince the potential electorate in present time societies, politics dominates in the mass media, which leads to creating new forms of linguistic manipulation. Thus, language plays a significant ideological role because it is an instrument by which, the manipulative intents of politicians become apparent [16].

\subsection{Multilingual/Language Pluralism}

All modern nations are more pluralistic in cultural, religious as well in political attitude [17]. In the general sense, pluralism is the acknowledgment of diversity and it is used, in different ways, and for a wide range of issues. Pluralism is the sense of interaction in which social groups show sufficient respect and understanding towards one another. 
Thus, linguistic pluralism is a term used to describe the acceptance of linguistic diversity, a scenario where all people (majority and minority) have the right to speak their own language in public and private domain without fear of condemnation. This is enforced through state policies to ensure the promotion and protection of these rights.

Multilingualism can be defined as an occurrence regarding an individual speaker who uses two or more languages, a community of speakers where two or more languages are used, or between speakers of two languages. Multilingualism basically arises due to the need to communicate across speech communities. Multilingualism is not a rare but a normal necessity across the world due to globalization and wider cultural communication. Moreover, multilingualism has various advantages includes accessibility to knowledge of other cultures, communication between different linguistic and cultural groups becomes easier, increases job opportunities, high cognitive development of a child and a broader world view.

\section{Language Policy, Monolingual Ethos and Multiculturalism in Ethiopia: Historical Contexts}

Getachew and Derib statedthat, the history of Ethiopian language policy (LP) was passing through two stages: defacto and de jure. The pre-1955 language policy was entirely a defacto language policy where Amharic, by common law, was the most crucial national language. Tewodros II changed trend of using Geez to write the Royal Chronicles into using Amharic. However, the language policy that Tewodros followed was a covert one as it was not supported by any legal document like a constitution. Yohanes IV, after coming to power, promoted the same language as Tewodros did in his quest for national unification of his empire. The third period, the reign of Minilik, can also be considered the continuation of the second period with relative modernization and expansion. The promotion of a monolingual language policy, namely the promotion of Amharic, continued covering a very wide area. Thus, the implementation of a covert language policy promoting one language from Tewodros II to Menelik II (1855-1955), legalized (overtly declared under the 1955 constitution) [8].

This implicit national status of the language was explicitly declared for the first time in the constitution of 1955. Haile Sellasie's government had a unique history from its predecessors with regard to language policy. It had a wellestablished language policy in a written constitution. The implementation of a single language policy was more prevalent in the area of administration, judiciary and education sectors. The Derg's language policy was a continuation of the previous language policy in a slightly different form. As it was stated so far, Amharic remained the main language that was used in the formal education, judiciary, administration and the media. From 1955 until 1991, Amharic enjoyed the constitutionally enshrined status of being the national language of Ethiopia. But, the ratification of the 1994 constitution, changed the history of the country with regard to language policy. In the constitution, Article 5 reads as;

1. All Ethiopian languages shall enjoy equal state of recognition.

2. Amharic shall be the working language of the Federal Government.

3. Members of the Federation may determine their respective languages.

Language as a characteristic is important in the sense that it is a key to keep their identity and all the other group characteristics. Currently, Ethiopia's language policy in the areas of administration, education, and the judiciary indicate that despite the official rhetoric of Official Multilingualism, the Amharic language still enjoys paramount dominance. This is not, however, to deny the existence of completely different stand by the government at all levels on language use. Thus, now each community has the right to use its language in all public arenas, at least, in its locality, which was unthinkable in the former regimes.

\section{Language Politics in Ethiopia: Experience from Wollo Oromo}

\subsection{Socio-Economic Significances of Multilingual Policy in Wollo Oromo}

There is a debate among scholars of language studies on the socio-economic significances of multilingual policy for local people. Some scholars argue that multilingual language policy enhance socio-economic development of local people. They argued that diversity of language contribute for the preservation of culture and indigenous knowledge which is the sources of development. On the other extreme, some scholars believe that multilingualism is a threat to national unity and homogenization. It created sectarian division among society. In this sub-section, an attempt was done to examine the socio-economic effects of multilingual policy from the experiences of Wollo Oromo. To verify this argument based on empirical data, 189 wollo Oromo residents were asked and their answers is as follow;

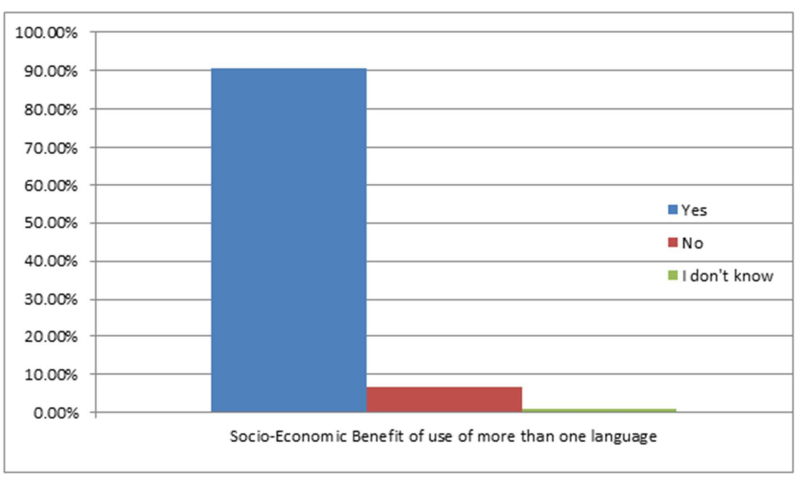

Figure 1. Socio-economic benefit of using more than one language. 
As the above bar chart, depicted $96.8 \%$ of the respondents believe that using more than one language has socioeconomic benefits. On the other hand few respondents, $6.8 \%$ of the respondents express their believing that the use of more than one language has no socio-economic benefits while $1 \%$ of the respondents answer as they do not know whether it has benefit or not. The data shows absolute majority of the respondents believe that the ability to use more than one language has socio-economic benefits for the users.

Participants of interviews and focus group discussions were also have the same believing concerning the socioeconomic benefits of using more than one language. One of the key interviews informants explain that language is economy because if you can speak different languages, you can easily communicate with different peoples and expand your market and job opportunity. Said the respondents, for example, individuals who speak only Amharic and individual who speak both Afaan Oromo and Amharic have no equal social relations and economic opportunity. The one who speak only Amharic has the opportunity to get jobs in office where working language is Amharic only while individuals who speak both Amharic and Afaan Oromo can get job opportunity in both offices where working language is Amharic as well as Afaan Oromo. In addition, the later individual can access to both Amharic and Afaan Oromo speakers social relations while the first one is limited to Amharic speaking society only.

In the same way scholars of linguistic study recommended that the use of local language enhances local socio-economic developments by enhancing the use of local knowledge. In addition, it enhances children innovation capacity. Hereunder the researchers tried to verify these concepts using empirical data from wollo Oromo who started to use their own language since 1991.

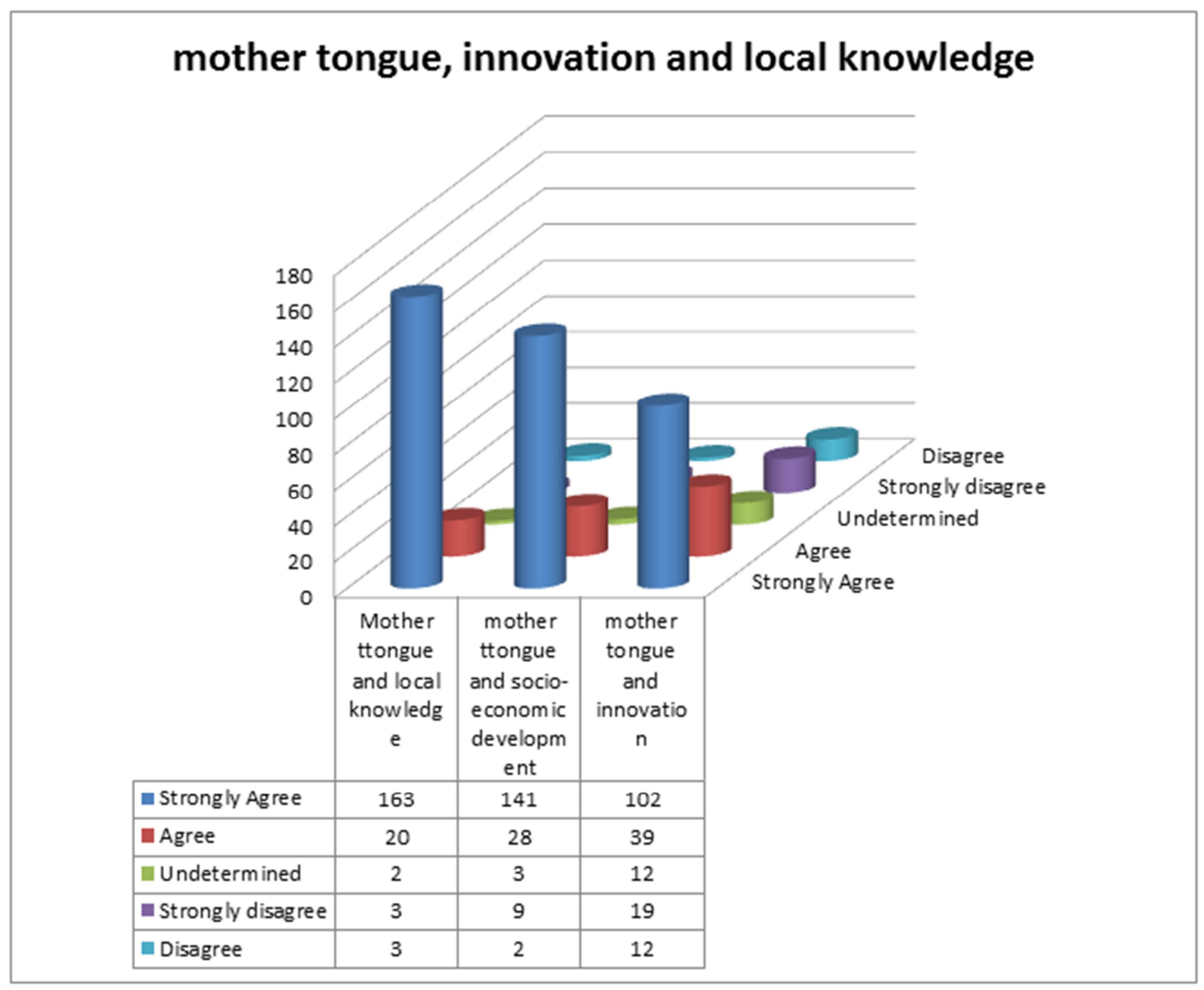

Figure 2. Mother tongue, innovation and local knowledge.

As the above bar chart depicted out of the total 190 respondents 163, 141 and 102 express as they are strongly agree the statement that the use of mother tongue enhance the use of local knowledge, socio-economic development and innovation respectively while 20,28 and 39 informants answer agree respectively. Insignificant numbers of respondents answer disagree and strongly disagree. From this, it is easy to conclude that the absolute majority of the informants have the opinion of the use of mother tongue for local administration and elementary school enhance local socio-economic development, exploration of local knowledge and developing children innovation capacity.

Participants of interviews and focus group discussions forward the same believing with elaborated explanation. For 
example, according to our informant ${ }^{1}$, using mother tongue language in different educational and administrative sectors brought various socio-economic importance in Wollo Oromo These includes, it strengths social relations both among community and with other society, it also enhances individuals capacity in education, it lead individuals to be innovative, and it helps community to aware about themselves.

\subsection{Multilingual Policy and Mother Tongue Education in Wollo Oromo}

Medium of Instruction in Educational policies are hotly debated in countries where the population speaks multiple languages either as a results of colonialism, war, multiethnic nation building or globalization. Some researchers suggests that educating students in their first language (Mother Tongue Education-MTE) can improve educational outcome on the basis that it supports sound meaning or meaning of symbols corresponding, facilitating understanding of new concepts and strengthens affective measures such as selfesteem, identity, motivation and creativity. In addition MTE preserves cultural and linguistic diversity and human rights.

On the other hand, some scholars argued that some traditional languages are not sufficiently developed to express modern concepts in fields such as mathematics and science. There is the perception that MTE undermines students' capacities to compete in global ideas and labour markets; and the concern that while MTE may, in theory, is preferable, resource constraints and teacher or parent opposition stand as significant obstacles to effective implementation.

Ethiopia is not exceptional from this reality. Due to multination building Ethiopian population speaks multiple languages as Thomas and Wondwosen more than 80 languages with 200 dialects. However, for a long period of time the Ethiopian language policy disregard this reality and implemented monolingual policy for primacy education until 1991 (except derg regime attempt to include some local languages in illiteracy campaign). In post 1991, new language policy introduced; multilingual in general and mother tongue education in particular. Therefore, in this subsection an attempt was made to examine the practices of multilingual policy in primary education among Wollo Oromo [4].

From kemissie town 180 community participants were asked the question that do you agree that learning in mother tongue can enhance educational quality and according to the above bar chart out of 180 total research participants 155,28 , 3 and 4 respondents responded strongly agree, agree, undetermined and strongly disagree. Absolute majority of the participants $(155+28)$ responded their perception of the use of mother tongue language in elementary school enhance educational quality. According to our informant ${ }^{2}$, using mother tongue language in different educational and

\footnotetext{
1 Interview with Chewaka Gudeta 22 September 2018.
}

2 Interview with Ahmed Hassen 22 September 2018. administrative sectors brought various socio-economic importance's in Wollo Oromo. These includes, it strengths social relations both among community and with other society, it also enhances individuals capacity in education, it lead individuals to be innovative, and it helps community to aware about themselves.

The previous language policy had various impacts on the individuals' right of self-determination in Wollo Oromo. It gives priority to Amharic language. During the previous regime, many Oromo's individuals failed to attend formal education since they were unable to understand Amharic language that they considered as lazy. Besides, it also results the lack of role model generation, which might assist the community's active engagement in education. Moreover, it affect psychological and attitude of the larger society in Wollo Oromo. If the son is unable to speak Amharic, his father considered him as backward and unknowledgeable. Therefore, said the participants of FGD, the current use of mother tongues solve this derogation partially.

\subsection{Multilingual Language Policy and the Auspices of Unity in Diversity (Wollo Oromo)}

There are two arguments concerning the nexus between language pluralism and national unity. The first argument is the views of scholars and politicians, which see diversity in general and language pluralism in particular as bottleneck for national unity. Proponents of this argument believe that multilingual language policy is a divisive force, which weakened national unity. Followers of this argument explain that to create strong national unity, there should be single national language recommending assimilation policy. The other group of scholars argued that in multilingual, multiethnic and multicultural society, recognition of language equality is significant for national unity since it enhance the feeling of belongingness of all diverse groups. In this study an attempt was made to examine this contending debates using practical example from Wollo Oromo.

As the above graph depicted out of 190 total respondents, $159,20,5,1$ and 5 answer strongly agree, agree, undetermined, disagree and strongly disagree respectively. Majority of the respondents answer strongly agrees followed with those answered agree. Insignificant numbers of respondents (only five respondents) answer strongly disagree followed by one respondent who answer disagree. Thus, absolute majority of the respondents believe that multilingual language policy in multiethnic and multicultural society is the backbone of national unity. As shown on the above graph absolute majority of the respondents (140 strongly agree +33 agree) argued that multilingual language policy strengthen national unity by enhancing feeling of belongingness among diverse groups in the society. Participants of interviews and FGD also confirmed the same arguments by saying that recognition of multilingualism strengthen national unity by enhancing nations and nationalities feeling of belongingness. The Wollo Oromo has the saying of 'we cannot negotiate on two interests: religious and language'. 


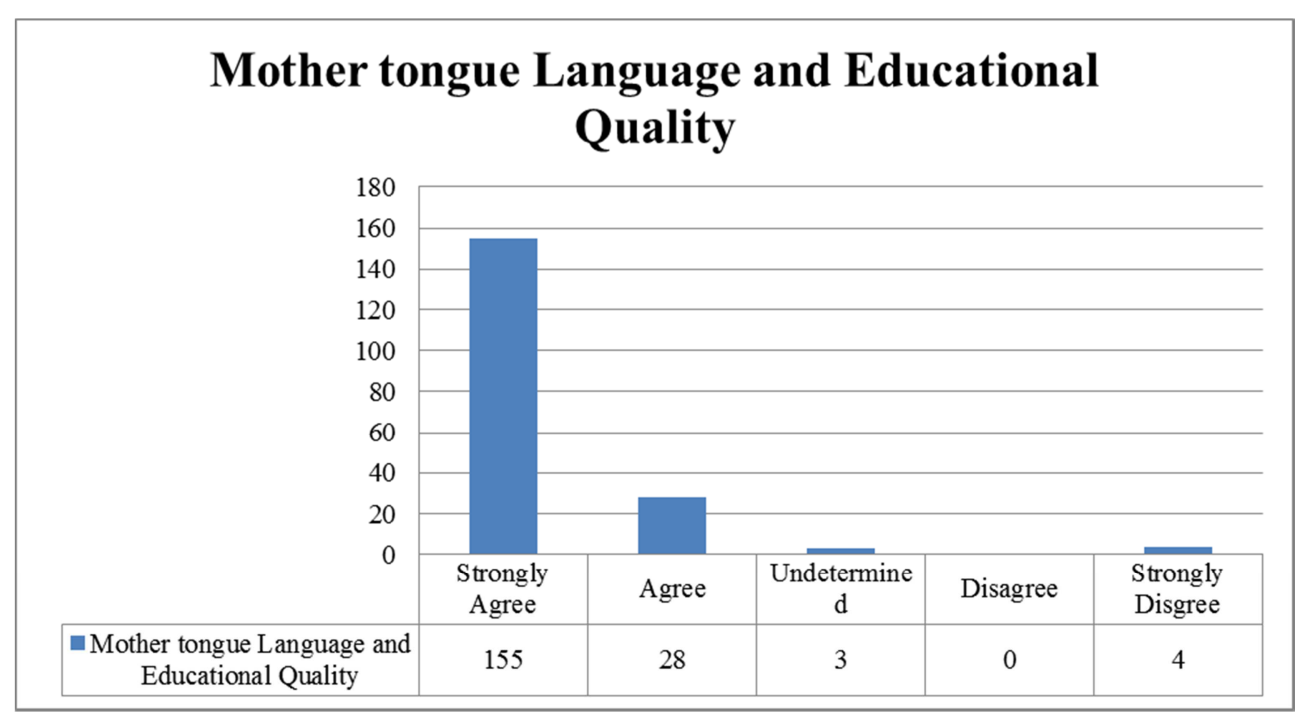

Figure 3. Mother tongue language and educational quality.

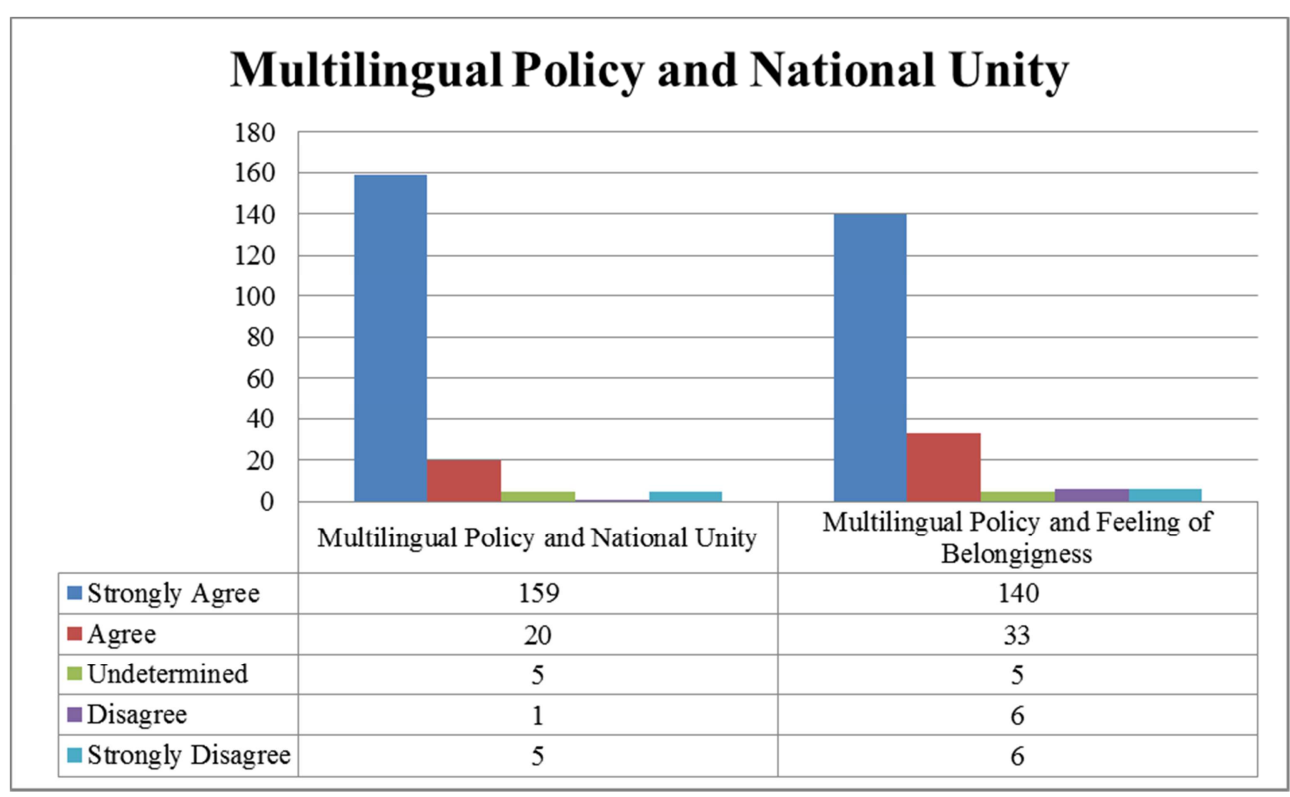

Figure 4. Multilingual policy and national unity.

\subsection{The Roles of Mother Tongue in Group Identity Construction in Wollo Oromo}

As Ghelawdewos Araia argued, Language does not just constitute a jumble of words that people use to communicate with one another. It is not also simply a formally structured speech with some rules and grammar. Language goes beyond all these technicalities and embodies rather expressions of conventions, beliefs, oral traditions, religious principles, talents, scientific and philosophical extrapolations, and reflections of names and identities (constant reminders of who we are as a people). J. N. Hattiangadi as cited in Glewade was argued, "Languages presuppose social conventions'. If we understand each other to any degree of sophistication, then it is because we share the conventions of some linguistic tradition. The argument for believing that social conventions are necessary for language - in some sense of the word "convention" - lies in the existence of diversity of languages" [18]. In this way, Ethiopia implemented multilingual language policy in which each nations and nationalities are allowed to construct their identities. This study focus on the roles of mother tongues specifically Afaan Oromo in Wollo Oromo identity construction. 


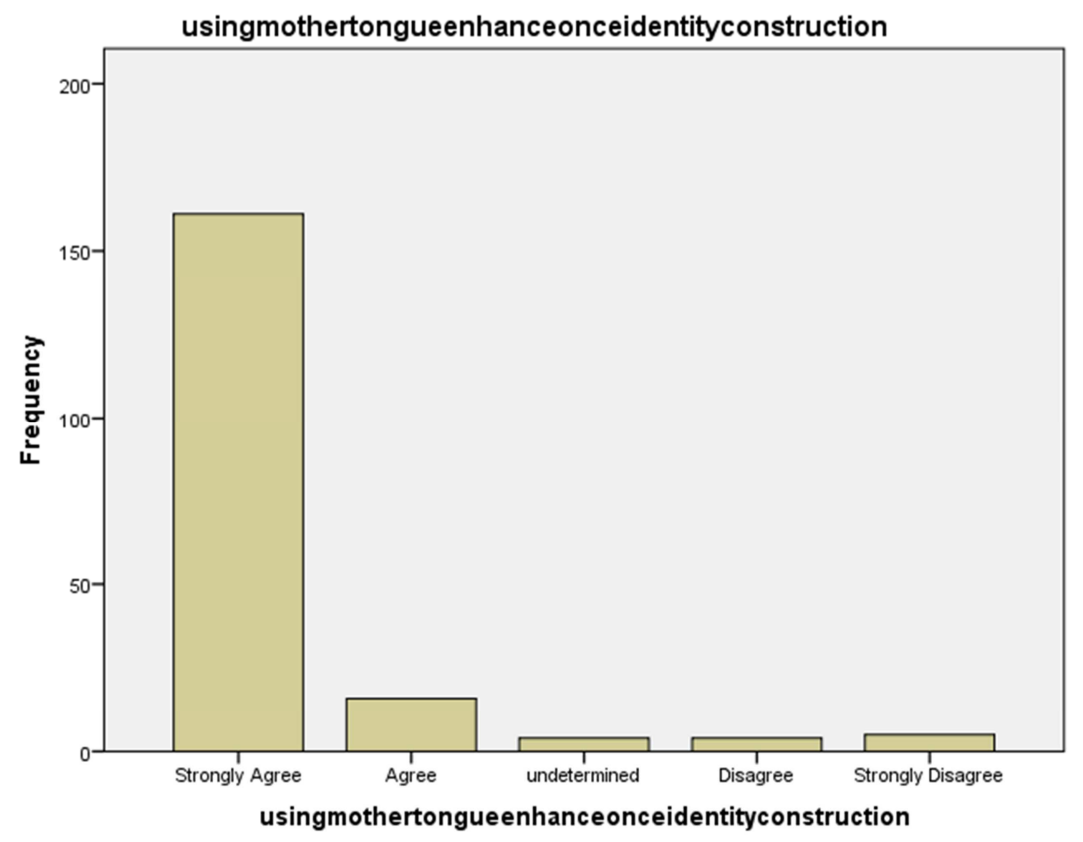

Figure 5. Use of mother tongue for identity construction.

As the above bar chart shows absolute majority of the respondents strongly agree (161) with the argument that using mother tongue enhances one's own identity construction followed by respondents answering agree. Very insignificant numbers of respondents answers disagree and strongly disagree. Thus, it is possible to conclude that the Wollo Oromo people believe that using mother tongue for local administration and education enhances one's own identity construction. In similar manners participants of interviews and focus group discussion ascertain that using one's own language (mother tongue) enhance groups identity construction. Since institutionalization of ethnicity, language ethnography in Wollo Oromo brought many changes in various aspects. These include, people began to use their mother tongue language in various levels, it enhances community participation in social, economic and political affairs, it increases an educated human power, it develops community economic capacity, it improve community livelihood. Moreover, it transforms community life from pastoral life to stable societal life. This is due the fact that people's livelihoods are improved, many people began to live stable living style.

\section{Challenges of Implementing Multilingual Language Policy in Wollo Oromo}

\subsection{Political Influences on Language Policy and Implementations (Politicization)}

Ethiopia is one of the linguistic diverse nations in Africa. It harbors more than eighty languages within its geopolitical boundary. This linguistically diverse nature of Ethiopia is part of the reason why the issue of language policy has been so contentious in Ethiopian history. Languages are strongly linked to politics in Ethiopia. The process of nation building and identity construction are directly connected to languages in Ethiopia. The roles of languages are at the hub of the current state building project of multination federalism. But, the main question in this study is that how much languages policy and development process is free from direct political influences in current Ethiopia. The researchers collected opinion from Wollo Oromo who started to use 'Afaan Oromo' for administrative and educational purposes in their zone after the introduction of multilingual language policy.

As the above bar chart shows out of 189 respondents 122 or $63.5 \%$ of the respondents agree as there is political influences on the introduction as well as implementation of the current multilingual language policy while 60 (31.3\%) and $7(3.7 \%)$ responded no and I don't know respectively. From the respondents' data majority of the respondents believe that the formulation as well as the implementation of current Ethiopian language policy is politically affected while small numbers of the respondents believe that the current Ethiopian language policy is free from political influences.

To verify the opinion differences among respondents of questionnaires the researchers use interviews and focus group discussions with elders, teachers, officials and community representatives. From the interviews some individuals believe that currently all peoples allowed to use and develop their own languages. All peoples are permitted the right to use their own languages for administration, courts and education in which the current use of Afaan Oromo in Wollo Oromo is the result of this policy. Since the introduction of multilingual language policy in 1995 in Ethiopia, the Wollo Oromo people use 'Afaan Oromo' for education up to College level and administration up to zone level which, is 
hitherto implemented in Ethiopian history.

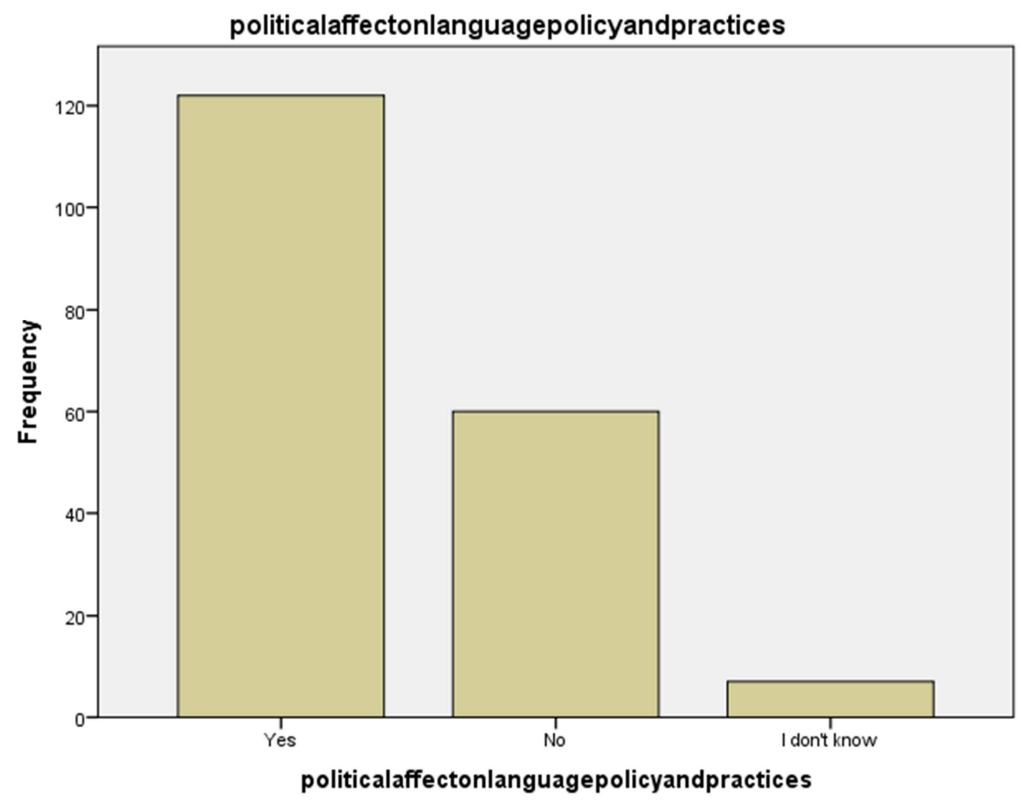

Figure 6. Political effects on language policy and practices.

On the other hand, majority of the respondents of questionnaires and interviews as well as participants of focus group discussion believe that multilingual language policy and practices in Ethiopia today is better than the previous policy but not free from political influences. The current Ethiopian language policy both in its introduction and in practices, is directly influenced by politics. The respondents explain that the current multilingual language policy, although, better than its predecessors, still give primacy for Amharic which is Ethiopian official language for a long period. Practically speaking, the process of language development in general and 'Afaan Oromo' in particular is politically limited. Language teaching and research is politically examined and no new development included without the green light from the politics. Generally, the finding shows that although, the current Ethiopian multilingual language policy is better than its predecessors, still Ethiopian language is under the spheres of influences of politics. Politicization of language still hinder the development of languages in Ethiopia in general and Afaan Oromo in particular.

\subsection{Monolingual Ethos in Ethiopia and Its Effects on Current Multilingual Policy}

Ethiopia, although, was multilingual, multicultural and multiethnic society implementing monolingual language until 1991. Since, 1991 the country changed its language policy toward multilingual in which all languages got equal constitutional recognition. All nations and nationalities are allowed to use their own languages or the language they choice for primary education and administration. However, the practice of multilingual policy is still affected by monolingual ethos Ethiopia experienced for a long period.
Therefore, hereunder the study was tried to identify the effects of monolingual ethos on current multilingual policy based on survey done on Wollo Oromo.

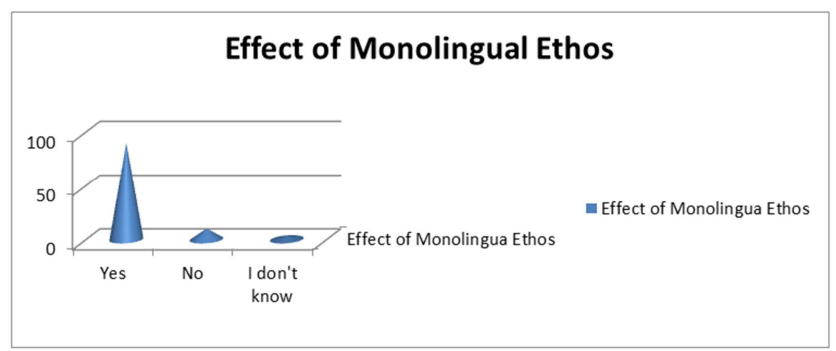

Figure 7. Effects of Monolingual Ethos.

As the above bar chart depicted that out of 189 respondents $164(86.8 \%)$ of Wollo Oromo believes that the previous monolingual ethos has a negative effects on the current multilingual language policy. On the other hand 19 $(10 \%)$ and $6(3.2 \%)$ of the respondents express their feeling as there is no effect and 'I don't know' respectively. Absolute majority of the respondents believe that history of monolingual language policy and practices have direct negative effects on the current Ethiopian multilingual language policy.

Respondents of interviews and participants of focus group discussion have also forwarded the same opinion with elaborated examples. According to information gained from FGD discussion there are various challenges for using mother tongue language in various sectors in Oromo nationality zone. These include lack of awareness about the use afaan Oromo language, the previous monolingual ethos influence, and lack of teaching materials support. Besides, there are group who are intentionally undermine afaan Oromo language as our 
informants ${ }^{3}$ stated. In addition, if you could not speak and write Amharic language properly, the lack of job opportunities is also another problem in the area. There are various saying and proverbs in the community, which discouraged local community to speak and learn afaan Oromo, received from previous monolingual ethos. This fact confirmed by three individuals cases that the researchers interviewed during field work that attest their child could not speak afaan Oromo although the father and mother are native afaan Oromo speakers. There is also fear to learn afaan Oromo since it considered as useless. Besides, there is no self-confidence among the community to learn and speak afaan Oromo. Again, there are various saying contributing for this:

"Afanoromobarateyoo Bate gadidabartebishansiihinobasuu. Yoomotummankunkufeafan

Oromo barachunmidhaguddaisiinirrangaha".

Some people specifically non-Oromo in various places such as at edir and religious center discouraging local community by saying if your children learn afaan Oromo, they could not go to Addis Ababa and Bahar Dar for work. Thus, do not send your child to Qube School. This language policy will be withered away with this government. In general, the previous monolingual ethos has had deep-rooted proverbs and sayings, which undermine all other languages in the country other than Amharic. This ethos accompanied with the current underground propaganda negatively affects the development of 'Afaan Oromo' in Wollo Oromo in particular and multilingualism in general.

The over politicization of language in Ethiopia accompanied with inertial of monolingual language ethos challenged the full implementation of multilingual communities. Rather previous national monolingual policy and official restriction replaced by regional monolingual language practices. Due to one or other reasons after the introduction of 'Afaan Oromo' as educational and administrative language in the area, Amharic leave the place, hence, regional monolingual prevails. The information gained from informants ${ }^{4}$ indicates that the attitude of undermining the use of afaan Oromo as mother tongue language continued in wollo Oromo. "Oromo could not able to rule people than keeping cattle", thus, do not confuse your children by sending to an afan Oromo School. Even there are sayings in Amharic "KemamarABCDyishalaltefmacheda" literally means it is better to work in the field than learning in Afaan Oromo or qube. From the above saying and proverb, one could understand that there was and is manifestation in the community that learning afaan Oromo is useless. Thus, this saying, which persisted in the community, discourages people not to use afaan Oromo in School.

In addition, the students and the teachers speak different language thus they couldn't understand each other. According to our informant ${ }^{5}$, in all high school in Kamise zone, all directors are Amharic speakers and native afaan

\footnotetext{
3 Interview with Chewaka Gudeta September, 2018.

4 Interview with Bekele Gabisa and Tadesse Maru15 September, 2018.

5 Interview with Garuma Jorgi 10 September, 2018.
}

Oromo speakers could not communicate with them, in case, if they may face a problem during teaching and learning process. At the same time, during a meeting when the students' families come and discuss some challenges of students' poor performance with school community, they couldn't understand the message from school principal since medium of instruction is Amharic. The other challenge includes lack of text book, syllabus and teacher guide in afaan Oromo language. For instance, in Kamise zone there is no syllabus and teacher guide in culture textbook from grade 1-4 and HP from 5-8 grades. In contrast, there are all materials available in Amharic language.

\section{Concluding Remarks}

The general objective of this research report is to assess the effects of Language politics, monolingual ethos and language pluralism in Wollo Oromo. To achieve the objective, both primary and secondary sources of data were collected and interpreted using both qualitative and quantitative methodologies of data analysis. As far as primary sources of data were concerned, first hand information was collected from target populations using multiple of methods and techniques of data collections. Fourteen close-ended questionnaires and three general questions were prepared and first hand, information was collected from 206 students. To substantiate and verify these quantitative data in-depth interviews was conducted with elders, students, teachers and social science professionals. As well as focus group discussion was held with teachers, students and community representatives. Furthermore, the primary data collected through multiple of methods and techniques were substantiated and verified by secondary sources. Using these data and conceptual framework, the researchers reached upon the following conclusions;

Ethiopia is one of the linguistic diverse nations in Africa. It harbors more than eighty languages within its geopolitical boundary. This linguistically diverse nature of Ethiopia is part of the reason why the issue of language policy has been so contentious in Ethiopian history. Languages are strongly linked to politics in Ethiopia. The process of nation building and identity construction are definitely connected to languages in Ethiopia. The roles of languages are at the hub of the current state building project of multination federalism. Since 1991 Ethiopia implemented multilingual language policy in which all languages get equal state recognition, all children afforded the right to learn in mother tongues, all nations and nationalities allowed to use their own languages or the language their choice for local administration.

Wollo Oromo nationality zone is the also the group of society who afforded these rights. The Oromo nationality zone use their own languages for both administrative and educational purposes. In this study, an assessment was done on the challenges and purposes of multilingual language policy and the finding prevail that multilingual policy is significant for local socio-economic development, exploration of local knowledge and innovation. The finding 
also prevail that learning in mother tongue enhances children learning capacity. The overall data shows that the Oromo nationality zonea people are happy with the current multilingual language policy. Nevertheless, the policy implementation is not free from challenges. Among others the implementation of multilingual language policy is challenged by monolingual ethos, politicization of language, lack of understanding and misconception of parents about the use of learning in mother language, attitudes toward local languages and lack of enough materials and teachers for the teaching of these languages. Hence, there is the need to depoliticize language and have comprehensive language academy which develop comprehensive curriculum and create awareness about significances of multilingualism.

\section{Conflict of Interests}

The authors have not declared any conflicts of interests.

\section{References}

[1] Keller, J. Edmond. (2005). Making and Remaking of state and Nation in Ethiopia. In Ricardo Rane Haremont (Eds.), Borders, Nationalism and the African state. Boulder, CO: Lynne Reinner.

[2] "Contradictory interpretation of Ethiopian History: The need for new Consensus", in, ed, by Turton, David, Ethnic federalism: The Ethiopian Experience in Comparative Perspectives: Oxford, James Currey, Athens: Ohio University Press and Addis Ababa: Addis Ababa University Press, (2006)

[3] Merera, Gudina, (2004), Ethiopia: Constraints to Transition and Democratization, in, ed, by Nhema, G. Alfred, The Quest for Peace in Africa, Transformation, Democracy and public Policy, OSSREA, Addis Ababa.

[4] Thomas, Bloor and Wondwosen, Tamrat (1996), Issues in Ethiopian Language Policy and Education, Journal of Multilingual and multicultural development, 17: 5, 321-338, DOI: $10.1080 / 01434639608666286$.

[5] Küspert-Rakotondrainy, Sophie. Language Policy and Identity in a Diverse Society: The Impact of Language of Instruction on Social Group Identity. A Comparative Case Study from Ethiopia.
[6] Milkessa Midhaga, (2011), Ethiopia's Choice of Federal Working Language and Its implications for non-Amharic Languages: The Case of Afaan Oromo, M. A Thesis, AAU.

[7] Farrokhi, Farahman, (2012), "Rethinking convenience sampling: defining quality criteria", theory and practice in language studies, Vol. 2, No. 4, pp 784-792.

[8] Getachew Anteneh and Derib A. 2006. "Language Policy in Ethiopia: History and Current Trends' In Ethiopian Journal of Education and Science" Vol. 2 No. 1, pp37-62.

[9] Schmidt, Ronald Sr. (2004). Language Policy, Identity Politics and Political Theory. Conference Papers- Western Political Science Association, 2004, Annual Meeting, Portland, OR, p1-24. 24p.

[10] Batibo, Herman M. 2005. "Language use optimisation as a strategy for national development". In Coleman, Hywel, ed. Language and Development: Africa and Beyond, Proceedings of the $7^{\text {th }}$ International Language and Development Conference Addis Ababa, 26-28 October 2005. Pp. 12-20.

[11] Baker, C. (2003). A Parents' and Teachers' Guide to Bilingualism, Multilingual Matters.

[12] Ellis, Elizabeth, (2007), Monolingualism: The Unmarked Case, Estudios De Sociolinguistica, 7 (2), Pp 173-196.

[13] Serratrice, Ludovica, (2015), Cross Linguistic Influences in Bilingual Development: when, why and how, https://www.researchgate.net/publication/263715104.

[14] Jessner, U. (2008). A DST model of multilingualism and the role of metalinguistic awareness, The modern language journal, 92 (2), Pp 270-283.

[15] Castro, D. C., Ayankoya, B., \& Kasprzak, C. (2011). The new voices/Nuevasvoces: Guide to cultural and linguistic diversity in early childhood. Baltimore, MD: Brookes.

[16] Rozina G and Karapetjana I. 2009. "The Use of Language in Political Rhetoric: Linguistic Manipulation”. Sosyal Bilimler Dergisi Mayıs, Say1: 19, ss. 111-122.

[17] NIKIFOROVA B, (2007), Language Policy and Language of Cultural Pluralism, Filosofija.

[18] Ghelawdewos, Araia, (2012), What Language should Ethiopians speaks? Institute of Development and Education for Africa, Inc. 